\title{
BMJ Open Development of an informational support questionnaire of transitional care for aged patients with chronic disease
}

\author{
Xiaoliu Shi (D) , ${ }^{1}$ Guiling Geng, ${ }^{1}$ Jianing Hua (D) , ${ }^{1}$ Min Cui, ${ }^{1}$ Yuhua Xiao, ${ }^{2}$ Juan Xie ${ }^{3}$
}

To cite: Shi X, Geng G, Hua J, et al. Development of an informational support questionnaire of transitional care for aged patients with chronic disease. BMJ Open 2020;10:e036573. doi:10.1136/ bmjopen-2019-036573

- Prepublication history and additional material for this paper are available online. To view these files, please visit the journal online (http://dx.doi. org/10.1136/bmjopen-2019036573).

Received 24 December 2019 Revised 21 September 2020 Accepted 30 September 2020

Check for updates

(c) Author(s) (or their employer(s)) 2020. Re-use permitted under CC BY-NC. No commercial re-use. See rights and permissions. Published by BMJ.

${ }^{1}$ School of Medical, Nantong University, Nantong, Jiangsu, China

${ }^{2}$ Affiliated Hospital of Nantong University, Nantong, China

${ }^{3}$ Department of Information Management, Affiliated Hospital of Nantong University, Nantong, China

Correspondence to Professor Guiling Geng; sxl1105421943@163.com

\section{ABSTRACT}

Objectives We developed an informational support questionnaire of transitional care (ISQTC) for aged patients with chronic disease and investigated its reliability and validity.

Setting This study was conducted in three large general hospitals in Nantong, Jiangsu Province, China.

Participants A total of 130 aged patients with chronic diseases, admitted into outpatient and inpatient departments from three hospitals in China, participated in the study. The inclusion criteria were: (1) patients must provide consent to participate; (2) being 60 years and above; (3) being diagnosed with at least one chronic disease and hospitalised more than two times within the last 1 year; (4) being able to listen, speak, read and write. The exclusion criteria were: (1) refusing to participate; (2) language expression and communication barriers (and having no caregiver to assist in participation); (3) being in intensive care or long-term hospitalisation.

Primary and secondary outcome measures The developed questionnaire was validated and tested for reliability. The content validity of the questionnaire was determined through experts' interviews and Delphi expert consultation, and the structure validity of the questionnaire was determined by performing exploratory factor analysis. The coefficient of reliability of the questionnaire was measured using Cronbach's alpha.

Results Through Delphi expert consultation and exploratory factor analysis, the questionnaire was reduced from four dimensions and 12 items to three dimensions and 11 items. A total of 130 patients responded to the questionnaire. The alpha coefficient was 0.747 .

Conclusion The ISQTC is a reliable and valid instrument for evaluating aged patients with chronic disease in transitional care.

Trial registration details ChiCTR1900020923. The trial was registered on 22 January 2019.

\section{INTRODUCTION}

Population ageing is a global phenomenon associated with the increase in the prevalence of chronic diseases among older adults. ${ }^{12}$ It is a major problem in many countries, which has increased financial expenditures and concern for diseases. ${ }^{3-6}$ It has also increased the readmission of elderly people with
Strengths and limitations of this study

- This study explored the information support in the transitional nursing process of elderly chronic diseases from the perspective of social support theory.

- This study developed the elderly chronic patients transitional care information support questionnaire to fill the research gap.

- This study excluded aged-chronic patients who cannot express their wishes, such as those in intensive care, long-term intubation or with language expression disorders.

- Cultural debugging is necessary in implementing the results of this study.

chronic diseases and emergency department visits, causing waste and misuse of medical resources. $^{78}$ Aged patients with chronic diseases, especially those with comorbidity, face a high risk of readmission and emergency admission and their caregivers bear the huge economic pressure and burden. ${ }^{8}$ To address this problem, transitional care interventions have been implemented with the common objective of reducing the rate of hospital readmission and emergency department visits.

Transitional care is a set of actions designed to ensure the coordination and continuity of healthcare as patients transfer between different locations or different levels of care within the same location. ${ }^{10}{ }^{11}$ It has been widely used for aged patients with chronic diseases and has been found to reduce the rate of readmission and adverse events. ${ }^{12} 13$ However, some researchers have pointed out that aged patients with chronic diseases who received transitional care are still adversely affected as a result of low intensity of information support in transitional care. ${ }^{14-16}$ These patients, who are repeatedly transferred from hospitals to their homes often do not get high-quality information support; resulting 
in a poor quality of continuing care, especially in medication information and discharge plan implementation. ${ }^{17-20}$ Therefore, for this special vulnerable group, we need to ensure high-intensity information support in carrying out their transitional care. ${ }^{21} 22$ This is cost-effective for the country, both in terms of economy and social benefits.

In China, population ageing is increasing rapidly, and the country has the highest number of older adults. In 2015, the population of people aged 65 and above in China reached 138 million, accounting for more than $10 \%$ of its entire population. ${ }^{23}$ China's population transformation model is similar to that of Japan. ${ }^{24}{ }^{25}$ In addition, due to an increase in population ageing rate, China's population ageing rate in the next 25 years is faster than that of Japan. ${ }^{25}$ Moreover, at the end of 2014 , the prevalence rate of chronic diseases in the elderly aged 65 and above in China was about $53 \%$, while their medical expenses were three times than that of the young, accounting for $30 \%$ to $35 \%$ of the total medical expenses in the country. ${ }^{25}$

The transitional care interventions are provided for continuity of information, medical care services and the doctor-patient relationship. Information continuity is the foundation of the quality of transitional care. Information support is also necessary for patients with chronic disease. It is a part of social support referred to as the act of helping the elderly chronic patients complete highquality transition by analysing, answering and providing information related to disease prevention, treatment and rehabilitation through all information that can be received, obtained and used by people. ${ }^{26-32}$ Researchers have proposed that timely, sufficient and targeted information support can improve patients' lifestyle, psychological status, treatment compliance, self-efficacy and quality of life, and reduce their disease uncertainty and help establish appropriate coping styles. ${ }^{32-34}$ However, only few researches are available on the relationship between information support and the health of elderly chronic patients in foreign countries. Some scholars have proposed that perceived information support is related to better self-care management, which is beneficial to the health of elderly people. ${ }^{35}$ Researchers have been concerned about improving transitional care by strengthening information support and much has been achieved. ${ }^{181936-38}$ However, most of the aged patients with chronic diseases still lack information support because of difficult challenges, such as information overload (they receive many health-related information), insufficient information (elderly patients receive information from only a particular source), information scatters (healthrelated information often has many resources; thus, they cannot receive all), information conflict (health-related information differs and aged patients do not know the right one to choose) and erroneous information (elderly patients are being deceived by commercial information). ${ }^{14} 1539$ Therefore, ensuring high-intensity information support in transitional care is the key to improving its quality and the outcome of discharge and reducing the burden of disease. ${ }^{40}$
The fundamental premise of improving the intensity of information support is to understand patients' preferred information sources, information transmission and receiving channels and information content to achieve accurate personalised support. However, information support assessment tools in transitional care for aged patients with chronic disease is still unavailable. The Care Transitions Measure (CTM) developed by Coleman et $a l_{,}{ }^{41}{ }^{42}$ and the Transition Care Programme (TCP) ${ }^{43}$ all evaluate the quality of continuous nursing from the perspective of elderly patients. Moreover, although some scholars have translated them, these evaluation tools are only aimed at determining the overall quality of transitional care and lack the evaluation indicators for the quality of transitional care structure and processes, especially the quality of information continuity. In China, transitional care quality is mainly evaluated through results from the telephone follow-up record book, family visit record, patients' clinical outcome and functional status, use of medical resources and patients' satisfaction with health services. Other indicators include medical expenses, survival rate, quality of life, caregiver's pressure and burden related to readmission and lack of information continuity quality evaluation tool of the process. ${ }^{34445}$

Thus, the purpose of this study was to develop a questionnaire and test its reliability and validity. Moreover, we aimed to help members of the transitional care team to understand the information sources, information transmission and reception and information content of the elderly chronic patients' preferences to meet the individual needs of the elderly patients with chronic diseases for information support and improvement of the quality of transitional care.

\section{MATERIALS AND METHODS Developing the scale}

First, the research team developed an item pool based on the literature review. We searched the PubMed, Web of Science and CNKI databases through August 2019. The PubMed search terms were ('transitional care' (MedicalSubject Headings (MeSH) terms) OR 'continuing care' (all fields) ) AND ('elderly' (MeSH terms) OR 'old' (all fields)) AND 'chronic disease' (MeSH terms) AND ('informational support' (all fields) OR 'information support' (all fields) OR 'social support' (MeSH terms)). Similar search terms were used to search the Web of Science and CNKI databases. The study was limited to subjects over 60 years old, not limited by language. A manual search was also carried out to identify pertinent data sources from the references of the identified studies. After discussion, the research group decided to adopt the theoretical framework of Xiao Shuiyuan's Social Support Rating Scale,${ }^{30}$ which is widely used in China, and combine it with four influencing factors of Liu Mancheng's research on the Factors Affecting the Adoption of Website for the Elderly. ${ }^{478}$ We used this combination to initially develop a questionnaire item pool from the three aspects of the information source, information transmission and receiving path and information content. The research team reviewed and 
revised the preliminary items repeatedly, and formulated a questionnaire that consists of four dimensions and 12 items.

Next, we supplemented the item content of the questionnaire through face-to-face interviews with 15 experts. These experts came from hospitals, nursing homes and universities, while their professional fields include clinical nursing, nursing management, elderly care, nursing education and information management. The experts are all deputy seniors or above and have considerable experience in elderly chronic diseases. The dimensions and items of the questionnaire after the content supplement are the same as the original, but the content became clearer and more practical.

\section{Validating the questionnaire}

\section{Study participants}

The study involved 20 experts and 130 elderly patients with chronic diseases. We used the Delphi anonymous consultation method to test the content of the questionnaire. ${ }^{490}$ The experts have worked for more than 6 years in the fields of nursing education, nursing management, clinical nursing, information management information education, among others. A researcher sent the designed anonymous consultation letter to the experts by email and collected them within 2 weeks. Thereafter, another researcher analysed the content of the collected consultation letter to ensure the anonymity of the questionnaire. The experts were not aware of the other participants. In total, two rounds of Delphi consultation were conducted, and the experts' response rate was $100 \%$.

To test the reliability and validity of the questionnaire, we selected the elderly chronic patients from three general hospitals in Nantong, including outpatients and inpatients, using the intentional sampling method for investigation. The inclusion criteria were: (1) only patients who have given their consent to participate; (2) being 60 years and above; (3) being diagnosed with at least one chronic disease and hospitalised more than two times within the last 1 year; (4) being able to listen, speak, read and write. The exclusion criteria were: (1) refusing to participate; (2) language expression and communication barriers (and having no primary caregiver to assist in participation); (3) being in intensive care or longterm hospitalisation. A total of 136 questionnaires were administered through email, 130 of which were returned with valid responses. These elderly chronic patients have experienced repeated hospitalisation and transitional care services, including the discharge plan, telephone follow-up, family visits, among others. All participants provided written informed consent and who can't write will be signed by caregivers.

\section{Measures}

\section{Determining the content of the questionnaire with Delphi}

The research group jointly designed the consultation letter with the following contents: (1) The introduction, which includes the research background, purpose, significance and instructions for filling the questionnaire. (2) The validity expert evaluation form of the informationalsupport questionnaire of transitional care (ISQTC), including the dimensions and items of the questionnaire.
We adopted a 5-point Likert scale to evaluate the degree of importance ( $5=$ very important, $4=$ important, $3=$ generally important, $2=$ unimportant and $1=$ very unimportant). ${ }^{51} 52$ Meanwhile, the table is provided with the column of modification opinions and increase/decrease opinions. (3) The questionnaire of experts' information, including the experts' demographic characteristics such as age, years of working, highest educational qualifications and their familiarity and judgement of the questionnaire. The degree of familiarity was divided into five (ie, very familiar to very unfamiliar). The judgement basis includes four aspects: intuitive selection, practical experience, theoretical analysis and references and the influence degree, which is arranged as follows: large, medium and small, respectively.

The positive coefficient of experts' options is measured using the questionnaire recovery rate. The recovery rate is more than $70 \%$, which can be classified as good enthusiasm of experts. ${ }^{50}$ The expert authority coefficient $(\mathrm{Cr})$ reflects the cognitive level of experts on research issues and is an important index in measuring the reliability of consulting results. Its calculation formula is: $\mathrm{Cr}=(\mathrm{Ca}$ $+\mathrm{Cs}) / 2$, where Ca represents the judgement coefficient of experts, Cs represents the familiarity coefficient of experts, and both were evaluated by the experts. ${ }^{53}$ The degree of experts' opinion is expressed by the mean of importance score (x), SD (s) and coefficient of variation $(\mathrm{CV}) .^{53} \mathrm{It}$ is generally believed that a greater mean of importance score results in smaller SD and coefficient of variation, while a more important indicator results to a more unified experts' opinion. In this study, the screening criteria were: mean value of importance score $>3.50$, and coefficient of variation $<20 \% .{ }^{53}$ The coordination degree of the experts' opinions mainly reflects the coordination degree of each expert on the index importance score. Generally, the Kendall harmony coefficient (W) is used to express the rater's reliability. The value range of $\mathrm{W}$ is 0 to 1 , where a larger value of $\mathrm{W}$ means a better coordination degree of experts' opinions.

We conducted two rounds of Delphi expert consultation. First, we performed statistics and analysis of the results of the first round of experts/consultation and reported a summary of experts' suggestions. Second, the research group discussed and modified the questionnaire dimensions and items according to the experts' suggestions and formulated the second round of consultation letter, which was subsequently given back to the experts. The details of the expert modification opinions are presented in the results section. Thereafter, we collected and analysed the results of the second round of experts' consultation to obtain the final ISQTC. After the discussion of the research group, the questionnaire was simplified into three dimensions and 11 items.

\section{Determining construction validity with EFA}

We investigated 130 aged patients with chronic diseases. The construct validity of the questionnaire was confirmed by EFA. Construct validity refers to the degree to which 


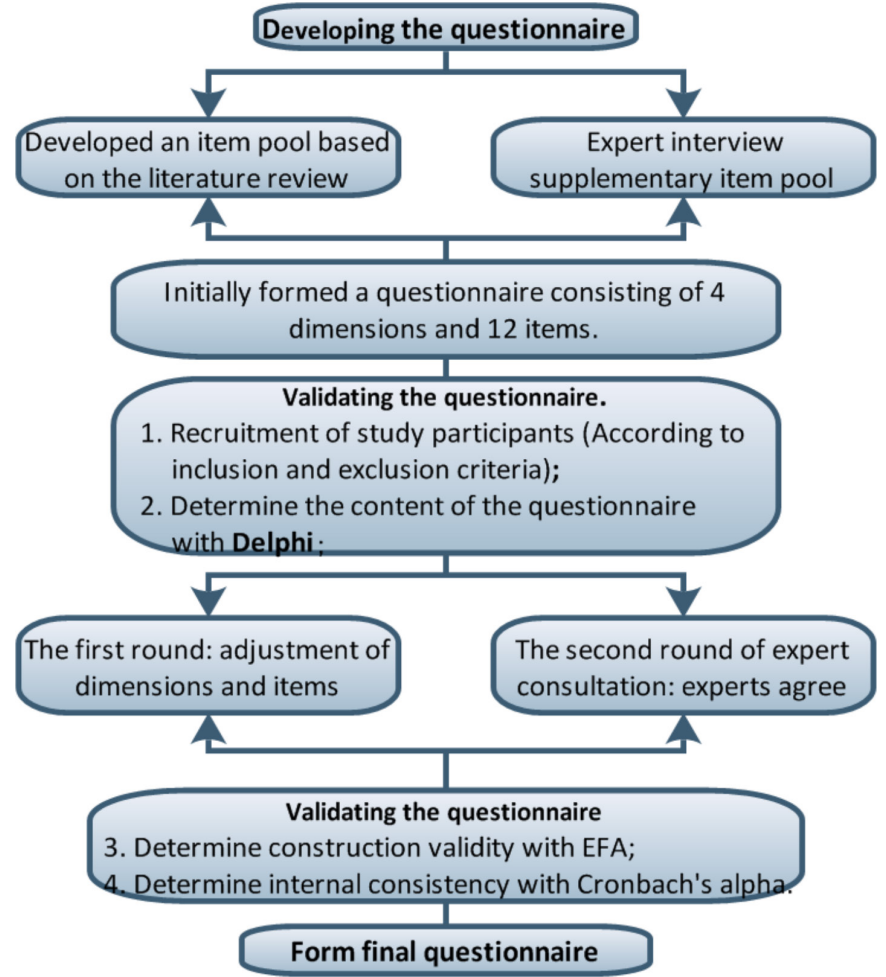

Figure 1 The flow chart. EFA, exploratory factor analysis

theoretical traits or concepts can be measured, that is, how many psychological traits can be explained by actual test scores. ${ }^{54}$ We used the Statistical Packages for the Social Sciences (SPSS) V.20 to analyse the pre-survey data and test the validity of the questionnaire. Kaiser-MeyerOlkin (KMO) and Bartlett test were used to test whether the questionnaire is suitable for factor analysis. ${ }^{54}$

\section{Determining internal consistency with Cronbach's alpha}

Reliability refers to the stability and consistency of the results measured by the questionnaire ${ }^{54} \mathrm{~A}$ greater reliability means a smaller error in the measurement standard. The reliability is usually tested by the reliability coefficient $\alpha$ created by L J Cronbach. Generally, it is considered that the minimum acceptable value of a factor is 0.65 , while 0.70 to 0.80 is quite good and 0.80 to 0.90 is very good. We used the internal consistency test (Cronbach $\alpha$ coefficient) to analyse the reliability of the questionnaire. ${ }^{54}$ The specific development process of the questionnaire is shown in figure 1.

\section{Statistical analysis}

We used EFA to test the validity of the questionnaire on the whole sample size $(n=130)$. The main factor analysis method is used to determine the factor whose eigenvalue is greater than 1 according to eigenvalue and scree plots. We determined factor reliability according to a Cronbach's alpha of $\geq 0.70 .^{54}$

\section{Patient and public involvement}

No participants were involved in the design and conduct of this study.

\begin{tabular}{|c|c|c|}
\hline & $\begin{array}{l}\mathrm{N} \text { or } \\
\text { mean } \pm S D\end{array}$ & $\%$ or (range) \\
\hline \multicolumn{3}{|l|}{ Gender $(n=20)$} \\
\hline Female & 3 & 15.0 \\
\hline Male & 17 & 85.0 \\
\hline \multicolumn{3}{|l|}{ Age $(n=20)$} \\
\hline & $45.8 \pm 8.8$ & (34.0 to 74.0 ) \\
\hline $30-39$ & 4 & 20.0 \\
\hline $40-49$ & 10 & 50.0 \\
\hline $50-59$ & 5 & 25.0 \\
\hline$>60$ & 1 & 5.0 \\
\hline \multicolumn{3}{|l|}{ Working years $(n=20)$} \\
\hline & $23.1 \pm 8.5$ & (6.0 to 36.0$)$ \\
\hline $6-12$ & 3 & 15.0 \\
\hline $13-19$ & 2 & 10.0 \\
\hline $20-26$ & 8 & 40.0 \\
\hline $27-33$ & 5 & 25.0 \\
\hline$>33$ & 2 & 10.0 \\
\hline \multicolumn{3}{|l|}{ Title $(n=20)$} \\
\hline Intermediate title & 3 & 15.0 \\
\hline Vice high title & 9 & 45.0 \\
\hline Highly professional title & 8 & 40.0 \\
\hline \multicolumn{3}{|l|}{$\begin{array}{l}\text { Highest academic qualifications } \\
(n=20)\end{array}$} \\
\hline Undergraduate & 9 & 45.0 \\
\hline Master & 8 & 40.0 \\
\hline Doctor and above & 3 & 15.0 \\
\hline \multicolumn{3}{|l|}{ Professional field $(n=20)$} \\
\hline Nursing education & 8 & 40.0 \\
\hline Nursing management & 7 & 35.0 \\
\hline Clinical nursing & 5 & 25.0 \\
\hline Information management & 3 & 15.0 \\
\hline Information education & 3 & 15.0 \\
\hline Other & 2 & 10.0 \\
\hline \multicolumn{3}{|l|}{ Administrative duties $(n=20)$} \\
\hline Vice president & 2 & 10.0 \\
\hline Dean of department & 2 & 10.0 \\
\hline Deputy dean of department & 1 & 5.0 \\
\hline Director of department & 2 & 10.0 \\
\hline Director of nursing department & 1 & 5.0 \\
\hline Head nurse & 6 & 30.0 \\
\hline Other & 6 & 30.0 \\
\hline
\end{tabular}

\section{RESULTS}

\section{Characteristics of consulting experts}

Table 1 describes the characteristics of Delphi consulting experts. Most of the experts are 40 to 49 years old, with an average working year of 23.1 years. Their professional titles are intermediate or above, and their educational qualification is undergraduate or above. The professional 
fields of experts involve nursing education, nursing management, clinical nursing, information management, information education, among others. Therefore, the research consulting experts have vast experience in nursing work and management, high professional and technical qualifications and educational level and a wide range of professional fields, which ensures the comprehensiveness and reliability of the research results. ${ }^{49}$

\section{General demographic characteristics of pre respondents}

Table 2 shows the general demographic characteristics of the participants. Women accounted for $61.5 \%$ of the participants. The average age of participants was 77 years (60.0 to 95.0), and $72.3 \%$ of them were married. Moreover, $24.6 \%$ of the older adults have a monthly household income of less than 2000 yuan, while $26.9 \%$ have 2000 to 4000 yuan, $15.4 \%$ have 4000 to 6000 yuan and $19.2 \%$ have more than 10000 yuan. In addition, $83.1 \%$ of older adults have one to three children. More than half of the older adults have six or more close friends to help them. The education level of the older adults is not high; $72.3 \%$ of them are below junior high school. Furthermore, 95.4\% of older adults are retired and not working. Except for regional restrictions, almost all the older adults have medical insurance, of which the new rural cooperative medical insurance accounts for $31.5 \%$, urban employee insurance accounts for $36.9 \%$, urban residents' insurance accounts for $11.5 \%$ and total public expense reimbursement accounts for $18.5 \%$.

\section{Delphi expert consultation results}

The response rate of two rounds of Delphi expert consultation was $100 \%$, and experts showed high enthusiasm. Tables 3 and 4 show the scores of dimensions and item importance in two rounds of Delphi expert consultation, respectively. It can be seen from tables 3 and 4 that in the two rounds of expert consultation results, the average score of questionnaire dimension and item importance (x) is more than 3.50 , and the coefficient of variation (CV) is less than $20 \%$, indicating that the experts' opinions are unified, so the item was not deleted. ${ }^{53}$

Tables 5 and 6 show the degree of agreement between the two rounds of experts' opinions. The Kendall concordance coefficient showed that the concordance coefficient of the second round of experts' consultation results is significantly higher than that of the first round, and the significance test results are $p<0.05$, which shows that the experts have a high degree of concordance with the opinions of items, and the consultation results are desirable.

The results of the first round of experts' consultation showed that the average score of the questionnaire dimension and item importance is 4.26 to 4.89 , and the coefficient of variation is $6 \%$ to $19 \%$. According to the screening criteria, there was no item deletion, indicating that the experts agree with the questionnaire items with a high degree of recognition but have different opinions on modification. In the first round of consultation, some experts suggested that the items in the fourth dimension
Table 2 General demographic characteristics of participants

\begin{tabular}{lcc}
\hline $\mathbf{n = 1 3 0}$ & N or mean \pm SD & \% or (range) \\
\hline $\begin{array}{l}\text { Gender } \\
\text { Female }\end{array}$ & \\
Male & 80 & 61.5 \\
\hline Age & 50 & 38.5 \\
\hline & & \\
$60-69$ & $77.0 \pm 10.1$ & $(60.0$ to 95.0$)$ \\
$70-79$ & 38 & 29.2 \\
$80-89$ & 37 & 28.5 \\
$\geq 90$ & 35 & 26.9 \\
\hline
\end{tabular}

Marital status

$\begin{array}{lrc}\text { Unmarried } & 1 & 0.8 \\ \text { Married } & 94 & 72.3 \\ \text { Divorce } & 0 & 0 \\ \text { Widowed spouse } & 35 & 26.9\end{array}$

Family monthly income (including

government subsidies)

$\begin{array}{lrc}\leq 2000 & 32 & 24.6 \\ 2000-4000 & 35 & 26.9 \\ 4000-6000 & 20 & 15.4 \\ 6000-8000 & 7 & 5.4 \\ 8000-10000 & 11 & 8.5 \\ \geq 10000 & 25 & 19.2\end{array}$

Past occupation

$\begin{array}{lcc}\begin{array}{l}\text { Government, enterprise and } \\ \text { business manager }\end{array} & 25 & 19.2 \\ \begin{array}{l}\text { Professional and technical } \\ \text { personnel }\end{array} & 20 & 15.4 \\ \text { General business personnel } & 12 & 9.2 \\ \text { Industrial workers } & 35 & 26.9 \\ \text { Migrant workers } & 7 & 5.4 \\ \text { Agricultural labourer } & 21 & 16.2 \\ \text { Unemployed or semi unemployed } & 10 & 7.7\end{array}$

Number of children

$\begin{array}{lcc}0 & 2 & 1.5 \\ 1 & 33 & 25.4 \\ 2 & 39 & 30.0 \\ 3 & 36 & 27.7 \\ 4 & 11 & 8.5 \\ 5 & 4 & 3.1 \\ 6 & 5 & 3.8\end{array}$

Close friends who can be helped and supported

\begin{tabular}{lrr} 
None & 7 & 5.4 \\
\hline $1-2$ & 14 & 10.8 \\
$3-5$ & 41 & 31.5 \\
6 or more & 68 & 52.4 \\
Degree of Education & & \\
Below primary school & 36 & 27.7 \\
\hline
\end{tabular}

Continued 


\begin{tabular}{|c|c|c|}
\hline$n=130$ & $\mathrm{~N}$ or mean $\pm \mathrm{SD}$ & $\%$ or (range) \\
\hline Primary school & 31 & 23.8 \\
\hline Junior middle school & 27 & 20.8 \\
\hline $\begin{array}{l}\text { High school or technical school or } \\
\text { technical secondary school }\end{array}$ & 17 & 13.1 \\
\hline Junior college or above & 19 & 14.6 \\
\hline \multicolumn{3}{|l|}{ Work situation } \\
\hline Not working & 124 & 95.4 \\
\hline At work & 6 & 4.6 \\
\hline \multicolumn{3}{|l|}{ Medical payment method } \\
\hline $\begin{array}{l}\text { New rural cooperative medical } \\
\text { system (rural insurance) }\end{array}$ & 41 & 31.5 \\
\hline $\begin{array}{l}\text { Basic medical insurance for urban } \\
\text { employees }\end{array}$ & 48 & 36.9 \\
\hline $\begin{array}{l}\text { Basic medical insurance for urban } \\
\text { residents }\end{array}$ & 15 & 11.5 \\
\hline Poverty relief & 0 & 0 \\
\hline Commercial medical insurance & 0 & 0 \\
\hline All public expense & 24 & 18.5 \\
\hline Full cost & 2 & 1.5 \\
\hline
\end{tabular}

should be integrated into the other three dimensions to make them more suitable for the theoretical framework, and the expressions of the other three dimensions should be modified, respectively, changing 'Objective Support', 'Subjective Support' and 'Individual Utilisation of

\begin{tabular}{|c|c|c|c|}
\hline Dimensions and items & $\mathbf{x}$ & $\mathbf{s}$ & CV (\%) \\
\hline (A) Objective support & 4.89 & 0.315 & 6 \\
\hline A1. Existing information sources & 4.84 & 0.375 & 8 \\
\hline $\begin{array}{l}\text { A2. Existing ways of transmitting } \\
\text { and receiving iinformation }\end{array}$ & 4.79 & 0.419 & 9 \\
\hline A3. Existing information content & 4.53 & 0.697 & 15 \\
\hline (B) Subjective support & 4.47 & 0.697 & 16 \\
\hline $\begin{array}{l}\text { B1. Practical application of } \\
\text { information source }\end{array}$ & 4.68 & 0.582 & 12 \\
\hline $\begin{array}{l}\text { B2. Practical application of } \\
\text { information dissemination and } \\
\text { reception ways }\end{array}$ & 4.63 & 0.597 & 13 \\
\hline $\begin{array}{l}\text { B3. Practical application of } \\
\text { information content }\end{array}$ & 4.63 & 0.684 & 15 \\
\hline $\begin{array}{l}\text { (C) Individual utilisation of } \\
\text { support }\end{array}$ & 4.74 & 0.733 & 15 \\
\hline C1. Individual access to information & 4.74 & 0.452 & 10 \\
\hline $\begin{array}{l}\text { C2. Individual utilisation of } \\
\text { information }\end{array}$ & 4.53 & 0.612 & 14 \\
\hline (D) Availability of information & 4.89 & 0.315 & 6 \\
\hline D1. Perceived ease of use & 4.26 & 0.806 & 19 \\
\hline D2. Perceived usefulness & 4.37 & 0.684 & 16 \\
\hline D3. Support availability & 4.47 & 0.612 & 14 \\
\hline D4. Design for elders & 4.37 & 0.597 & 14 \\
\hline
\end{tabular}

Table 4 Second-round item and dimension importance score

\begin{tabular}{|c|c|c|c|}
\hline Dimensions and items & $x$ & $\mathbf{s}$ & $\begin{array}{l}\text { CV }(\% \\
)\end{array}$ \\
\hline $\begin{array}{l}\text { (A) Objective information } \\
\text { support }\end{array}$ & 5.00 & 0.000 & 0 \\
\hline $\begin{array}{l}\text { A1. Existing information } \\
\text { providers }\end{array}$ & 4.94 & 0.236 & 5 \\
\hline $\begin{array}{l}\text { A2. Existing ways of } \\
\text { transmitting and receiving } \\
\text { information }\end{array}$ & 4.39 & 0.502 & 11 \\
\hline A3. Existing information content & 4.78 & 0.428 & 9 \\
\hline $\begin{array}{l}\text { A4. Practical application of } \\
\text { information source }\end{array}$ & 4.22 & 0.428 & 10 \\
\hline $\begin{array}{l}\text { A5. Practical application of } \\
\text { information dissemination } \\
\text { and reception ways }\end{array}$ & 4.22 & 0.428 & 10 \\
\hline $\begin{array}{l}\text { A6. Practical application of } \\
\text { information content }\end{array}$ & 5.00 & 0.000 & 0 \\
\hline $\begin{array}{l}\text { (B) Subjective experience of } \\
\text { information support }\end{array}$ & 4.17 & 0.383 & 9 \\
\hline $\begin{array}{l}\text { B1. Individual access to } \\
\text { information }\end{array}$ & 4.17 & 0.383 & 9 \\
\hline B2. Perceived ease of use & 4.89 & 0.323 & 7 \\
\hline B3. Support availability & 4.83 & 0.383 & 8 \\
\hline $\begin{array}{l}\text { (C) Individual utilisation of } \\
\text { information support }\end{array}$ & 4.11 & 0.323 & 8 \\
\hline C1. Design for elders & 4.94 & 0.236 & 5 \\
\hline C2. Perceived usefulness & 4.89 & 0.323 & 7 \\
\hline
\end{tabular}

Support' into 'Objective Information Support', 'Subjective Experience of Information Support' and 'Individual Utilisation of Information Support'. These suggestions were adopted through discussion in the research group. According to the content of the options, some experts suggested that the secondary indicator 'existing information source' in the dimension of 'objective support' should be changed to 'existing information providers'; thus, the research group adopted and modified it after discussion. To make the questionnaire dimension and item content more suitable, experts proposed to adjust the item content of each dimension appropriately. In addition, several experts provided suggestions for the modification of the expression methods and the connotation of items in the three-level indicators. After consulting the literature and discussion, the research group made appropriate modifications.

The results of the second round of consultation showed that the experts' opinions tended to be the same. The

Table 5 The first round of experts' consensus

\begin{tabular}{lrrrrc}
\hline & $\mathbf{N}$ & $\mathbf{W}$ & $\mathbf{X}^{2}$ & df & P value \\
\hline Dimensions & 4 & 0.160 & 8.661 & 3 & 0.034 \\
Items & 12 & 0.108 & 21.460 & 11 & 0.029 \\
\hline
\end{tabular}




\begin{tabular}{lrrrrr}
\hline \multicolumn{7}{c}{ Table 6} & \multicolumn{6}{c}{ The second round of experts' consensus } \\
\hline & $\mathbf{N}$ & $\mathbf{W}$ & \multicolumn{1}{c}{$\mathbf{X}^{\mathbf{2}}$} & $\mathbf{d f}$ & $\mathbf{P}$ value \\
\hline Dimensions & 3 & 0.505 & 20.182 & 2 & 0.000 \\
Items & 11 & 0.515 & 102.950 & 10 & 0.000 \\
\hline
\end{tabular}

highest average score of the questionnaire dimension and item importance was 5.00, and the highest coefficient of variation was $11 \%$. There was no deletion or modification of the questionnaire dimension and item. After two rounds of experts' consultation, the questionnaire with three dimensions and 11 items was formed.

\section{Exploratory factor analysis}

Table 7 shows the KMO and Bartlett test results. The $\mathrm{KMO}$ value is 0.718 , indicating moderate degree, that is, 'informational support questionnaire of transitional care (ISQTC) for aged patients with chronic disease' is suitable for factor analysis; Bartlett's approximate $\chi^{2}$ distribution of the spherical test is 556.023, freedom degree is 55 and significance probability value is $\mathrm{p}=0.000<0.05$, indicating significant level. This shows that the 11 item variables of 'volume' have common factors and are suitable for factor analysis. ${ }^{54}$

Table 8 presents the results of ISQTC exploratoryfactor analysis EFA). It can be seen from table 8 and figure 2 that in EFA, there are three factors whose eigenvalue is greater than 1. The construct of common factor one is called 'objective information support', which includes six topics: C1, C2, C3, C4, C5 and C6. The construct of common factor two is called 'subjective experience of information support', which includes three topics: C7, C8 and C9. The construct of common factor three is called 'individual utilisation of information support', which includes C10 and C11. The eigenvalues of each factor before rotation were $3.676,2.289$ and 1.313, respectively. The eigenvalues after rotation by direct skew method were 3.461, 2.106 and 1.711 , respectively. The combined interpretation variance of the three factors was $66.159 \%$, which indicate that their construction reliability was good. ${ }^{54}$

\section{Internal consistency of the final questionnaire}

It can be seen from table 9 that the overall $\alpha$ factor value of the questionnaire was 0.747 , and the $\alpha$ factor value of the three dimensions was 0.713 to 0.806 , all of which are greater than 0.70 . The results showed that the $\alpha$ factor of the questionnaire was good, so it can be considered that the questionnaire has good reliability and reliable results. ${ }^{54}$ The final questionnaire 'The Informational Support Questionnaire of Transitional Care for Aged

\begin{tabular}{lll}
\hline Table 7 & Kaiser-Meyer-Olkin and Bartlett test & \\
\hline Kaiser-Meyer-Olkin & Sampling suitability index & $\mathbf{0 . 7 1 8}$ \\
\hline Bartlett spherical test & Approximate $\chi^{2}$ distribution & 556.023 \\
& df & 55 \\
\hline & Sig. & 0.000 \\
\hline
\end{tabular}

Patients with Chronic Disease' has been formed. The content, usage, scoring method and the translation version of the questionnaire have been uploaded as online supplemental file 1 ).

\section{DISCUSSION}

The elderly patients, with an average age of 77 years, were from the outpatient and inpatient departments of the three large general hospitals in Nantong, Jiangsu Province, China. They have been hospitalised repeatedly and experienced many transitions. Therefore, this sample is representative of elderly patients with chronic diseases.

In the two rounds of Delphi expert correspondence, no items were deleted in the questionnaire, and only the dimensions and items of the questionnaire were adjusted and modified according to the experts' opinions. The screening criteria were that the mean value of importance score is greater than 3.5, and the coefficient of variation is less than $20 \%$. It was determined based on previous studies ${ }^{5556}$ and the item screening indicators may lack sensitivity to some extent. However, this questionnaire establishes an item pool on the basis of a literature review and makes preliminary modifications to supplement the item pool through an interview with experts. The experts were specialised in geriatric medicine, geriatric nursing, clinical nursing, information management, nursing management, rehabilitation, community nursing and other professional fields; thus, there is a certain degree of credibility in the content of this questionnaire. Although no item was deleted after two rounds of experts' consultation, the average score of the importance of items in the second round was significantly higher than that in the first round, and the coefficient of variation was significantly lower than that in the first round; thus, the experts' opinions were consistent.

The Delphi method has been widely accepted and used in previous studies in drawing experts' opinions. Some studies reported that the number of rounds of expert consultation or the consensus rate of experts on a certain point of view is considered as the judgement standard of the Delphi method; however, this judgement standard is only applicable to some criteria or the consensus of experts, and it is unable to distinguish the importance of each item in the questionnaire. ${ }^{57}$ Some experts have questioned the value of using the percentage measure, arguing that stability through a series of rounds of response is a more reliable indicator of consensus. ${ }^{58}$ Meanwhile, Delphi's importance scoring standard 1 to 5 has been widely used in China. The mean value of the importance score is more than 3.5, and the coefficient of variation is less than $20 \%$. It is also a common item screening standard in Chinese questionnaire. Thus, this improved Delphi method has been widely used, which not only reduces the number of experts' rounds but also gradually simplifies the scoring standard and obtains efficient decision-making.

This study will play a key role in guiding the elderly chronic disease transitional care workers in the clinical environment. First, through the questionnaire survey of the elderly chronic 
Table 8 Summary of exploratory factor analysis results of 'ISQTC'

\begin{tabular}{|c|c|c|c|c|}
\hline \multirow[b]{2}{*}{ Item variables and questions } & \multicolumn{3}{|c|}{$\begin{array}{l}\text { The structure matrix of the direct skew method after } \\
\text { skewing the rotating shaft }\end{array}$} & \multirow[b]{2}{*}{ Commonality } \\
\hline & $\begin{array}{l}\text { Objective } \\
\text { information } \\
\text { support }\end{array}$ & $\begin{array}{l}\text { Subjective } \\
\text { experience of } \\
\text { information } \\
\text { support }\end{array}$ & $\begin{array}{l}\text { Individual } \\
\text { utilisation of } \\
\text { information } \\
\text { support } \\
\end{array}$ & \\
\hline $\begin{array}{l}\text { C5. In what ways have you obtained the health-related } \\
\text { information you need? }\end{array}$ & 0.834 & 0.049 & 0.106 & 0.709 \\
\hline $\begin{array}{l}\text { C6. What health information and content can help you with your } \\
\text { health problems? }\end{array}$ & 0.761 & -0.138 & -0.103 & 0.608 \\
\hline C3. What are the health information you are exposed to? & 0.748 & -0.041 & 0.111 & 0.573 \\
\hline $\begin{array}{l}\text { C1. Who do you think can help you with health information when } \\
\text { you need it? }\end{array}$ & 0.747 & 0.294 & -0.275 & 0.721 \\
\hline $\begin{array}{l}\text { C8. When encountering health-related problems, I think it's easy } \\
\text { to get relevant information. }\end{array}$ & 0.040 & 0.789 & 0.094 & 0.633 \\
\hline $\begin{array}{l}\text { C7. When I encounter problems, I will actively seek help and } \\
\text { information. }\end{array}$ & 0.047 & 0.652 & 0.349 & 0.549 \\
\hline $\begin{array}{l}\text { C11. I think I can get health-related information more easily } \\
\text { through modern ways (such as Internet, mobile phone, and so } \\
\text { on). }\end{array}$ & 0.115 & 0.115 & 0.862 & 0.769 \\
\hline C10. I think a lot of health information is specifically for the elderly. & -0.088 & 0.218 & 0.786 & 0.674 \\
\hline Cumulative explained variance $\%$ & & & & 66.159 \\
\hline
\end{tabular}

ISQTC, informational support questionnaire of transitional care.

patients who have experienced repeated transition, we can evaluate the status of information support in transitional care and understand the information support level of the elderly chronic patients. Second, according to the content of the questionnaire, we can know the understanding and utilisation degree of the elderly chronic patients on the information source, information transmission and receiving way,

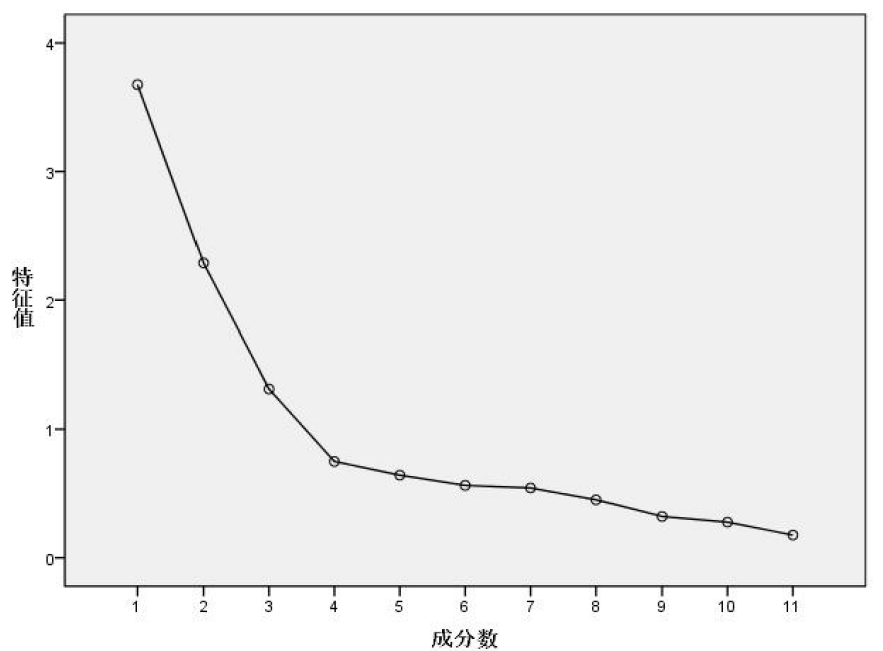

Figure 2 The scree plot. information content and the real needs on the information support source, content and way.

Through the questionnaire survey, transitional care workers can easily find out the weak links in information support of elderly chronic patients. On the information source, we can find out the more trusted information provider, the more easily accepted information transmission and reception as well as the easily obtained information content of the elderly chronic patients. Additionally, we can ascertain other transitional care-related personnel who are not accepted and trusted by the elderly, the information transmission and reception pathway which are difficult to be accepted and learnt as well as the information content which is needed but

\begin{tabular}{|c|c|c|}
\hline Questionnaire dimensions & Cronbach $\alpha$ & Items (N) \\
\hline (A) Objective information support & 0.806 & 6 \\
\hline $\begin{array}{l}\text { (B) Subjective experience of } \\
\text { information support }\end{array}$ & 0.731 & 3 \\
\hline $\begin{array}{l}\text { (C) Individual utilisation of } \\
\text { information support }\end{array}$ & 0.713 & 2 \\
\hline Questionnaire overall & 0.747 & 11 \\
\hline
\end{tabular}

ISQTC, informational support questionnaire of transitional care. 
not obtained. Therefore, the transitional care team members can provide targeted interventions for elderly patients with chronic diseases according to the results of information support evaluation, to improve the quality of transitional care, reduce the readmission rate of elderly patients with chronic diseases and save the consumption of medical resources and financial expenditure.

The practical application of this questionnaire in clinical work needs further study, and we hope to continue to report the follow-up results.

\section{Strengths and limitations}

The originality of this study is to look at the elderly chronic disease transitional care from the sociological perspective and develop the questionnaire ISQTC according to the social support theory. This study hopes to explore more potential resources from the perspective of sociology and promote the continuity of information in transitional care, to improve the quality of transitional care and the outcome of discharge. As for the reliability of ISQTC, Cronbach's $\alpha$ coefficient of each factor and the whole scale indicates sufficient internal consistency. The results of the EFA confirmed the validity of the concept behind the questionnaire. Therefore, the ISQTC obtained from this study is considered to be a sufficient, reliable and valid questionnaire, which can effectively evaluate the adequacy of information support in continuing care for elderly patients with chronic diseases.

The limitations of this study include the following two aspects: First, this study only represents the elderly chronic disease patients who are able to listen, speak, read and write, and lacks the representativeness for the elderly chronic disease patients who cannot express their wishes, such as those who need long-term tracheal intubation and intensive care. Second, the results of this study only apply in the context of Chinese culture. Cultural debugging is necessary in the implementation of the results of this study.

\section{CONCLUSION}

The ISQTC is a reliable and valid instrument for measuring informational support of aged patients with chronic disease. The questionnaire survey is helpful to understand the information provider, the way of information transmission and reception and the content of information preferred by the aged patients with chronic diseases, to provide suggestions and basis for the implementation of transitional care and improve its quality. It is also beneficial to promote information exchange, reduce the consumption of medical resources and government financial expenditure.

Acknowledgements We would like to thank Editage company for its contribution polishing service.

Contributors SX and GG participated in the design, project management, investigation and manuscript writing of the study. $\mathrm{JH}$ contributed to the research methods, supervised and confirmed the research results and reviewed the contributions. JH and MC have contributed to data collation and formal analysis. JX and $\mathrm{YX}$ contributed to data collection. All the authors agreed to the final version of the manuscript.
Funding This research protocol is a subproject of the National Social Science Foundation Project of China, which has been supported by the National Social Science Foundation of China (18BSH159).

Competing interests None declared.

Patient consent for publication Not required.

Ethics approval The study was conducted with the approval of the ethics committee of Nantong University Affiliated Hospital, Nantong City, Jiangsu Province, China (Approval No. 2018-K042).

Provenance and peer review Not commissioned; externally peer reviewed.

Data availability statement Data are available upon reasonable request.

Supplemental material This content has been supplied by the author(s). It has not been vetted by BMJ Publishing Group Limited (BMJ) and may not have been peer-reviewed. Any opinions or recommendations discussed are solely those of the author(s) and are not endorsed by BMJ. BMJ disclaims all liability and responsibility arising from any reliance placed on the content. Where the content includes any translated material, BMJ does not warrant the accuracy and reliability of the translations (including but not limited to local regulations, clinical guidelines, terminology, drug names and drug dosages), and is not responsible for any error and/or omissions arising from translation and adaptation or otherwise.

Open access This is an open access article distributed in accordance with the Creative Commons Attribution Non Commercial (CC BY-NC 4.0) license, which permits others to distribute, remix, adapt, build upon this work non-commercially, and license their derivative works on different terms, provided the original work is properly cited, appropriate credit is given, any changes made indicated, and the use is non-commercial. See: http://creativecommons.org/licenses/by-nc/4.0/.

\section{ORCID iDs}

Xiaoliu Shi http://orcid.org/0000-0001-9877-3973

Jianing Hua http://orcid.org/0000-0002-0691-0764

\section{REFERENCES}

1 Thiede B, Brown DL, Sanders SR, et al. A demographic deficit? local population aging and access to services in rural America, 1990-2010. Rural Sociol 2017;82:44-74.

2 Du X, Patel A, Anderson CS, et al. Epidemiology of cardiovascular disease in China and opportunities for improvement: JACC international. J Am Coll Cardiol 2019;73:3135-47.

3 Prince MJ, Wu F, Guo Y, et al. The burden of disease in older people and implications for health policy and practice. Lancet 2015;385:549-62.

4 Bauer UE, Briss PA, Goodman RA, et al. Prevention of chronic disease in the 21st century: elimination of the leading preventable causes of premature death and disability in the USA. Lancet 2014:384:45-52.

5 Charvat $\mathrm{H}$, Goto $\mathrm{A}$, Goto $\mathrm{M}$, et al. Impact of population aging on trends in diabetes prevalence: a meta-regression analysis of 160,000 Japanese adults. J Diabetes Investig 2015;6:533-42.

6 Sudharsanan N, Ali MK, Mehta NK, et al. Population aging, macroeconomic changes, and global diabetes prevalence, 19902008. Popul Health Metr 2015;13:33.

7 Street M, Berry D, Considine J. Frequent use of emergency departments by older people: a comparative cohort study of characteristics and outcomes. Int J Qual Health Care 2018;30:624-9.

8 Wang C, Li F, Wang L, et al. The impact of population aging on medical expenses: a big data study based on the life table. Biosci Trends 2018;11:619-31.

9 Horney C, Capp R, Boxer R, et al. Factors associated with early readmission among patients discharged to post-acute care facilities. J Am Geriatr Soc 2017;65:1199-205.

10 Reese RL, Clement SA, Syeda S, et al. Coordinated-transitional care for veterans with heart failure and chronic lung disease. J Am Geriatr Soc 2019;67:1502-7.

11 Dresden SM, Hwang U, Garrido MM, et al. Geriatric emergency department innovations: the impact of transitional care nurses on 30 day readmissions for older adults. Acad Emerg Med 2020;27:43-53.

12 Finlayson K, Chang AM, Courtney MD, et al. Transitional care interventions reduce unplanned Hospital readmissions in high-risk older adults. BMC Health Serv Res 2018;18:956.

13 Donovan JL, Kanaan AO, Gurwitz JH, et al. A pilot health information technology-based effort to increase the quality of transitions from skilled nursing facility to home: compelling evidence of high rate of adverse outcomes. J Am Med Dir Assoc 2016;17:312-7. 
14 Jeffs L, Saragosa M, Law M, et al. Elucidating the information exchange during interfacility care transitions: insights from a qualitative study. BMJ Open 2017;7:e015400.

15 Hestevik CH, Molin M, Debesay J, et al. Older persons' experiences of adapting to daily life at home after hospital discharge: a qualitative metasummary. BMC Health Serv Res 2019;19:224.

16 Lapointe-Shaw L, Bell CM, Austin PC, et al. Community pharmacy medication review, death and re-admission after hospital discharge: a propensity score-matched cohort study. BMJ Qual Saf 2020;29:41-51.

17 Ensing HT, Koster ES, Dubero DJ, et al. Collaboration between hospital and community pharmacists to address drug-related problems: the HomeCoMe-program. Res Social Adm Pharm 2019;15:267-78.

18 Reeves MJ, Hughes AK, Woodward AT, et al. Improving transitions in acute stroke patients discharged to home: the Michigan stroke transitions trial (MISTT) protocol. BMC Neurol 2017;17:115.

19 Reeves MJ, Fritz MC, Woodward AT, et al. Michigan stroke transitions trial. Circ Cardiovasc Qual Outcomes 2019;12:e005493.

20 National Health and Health Commission of the people's Republic of China. Aging is a challenge and an opportunity for cities, 2016. Available: http://www.nhc.gov.cn/jkj/s5879/201611/e67bdb87ae8b 4b3d913117a5e1be0dc1.shtml; [Accessed 5 Dec 2019].

21 Qiu X, Zhao T, Kong Y, et al. Influence of population aging on balance of medical insurance funds in China. Int $J$ Health Plann Manage 2020;35:152-61.

22 Chen R, Xu P, Song P, et al. China has faster PACE than Japan in population aging in next 25 years. Biosci Trends 2019;13:287-91.

23 National Health and Health Commission of the people's Republic of China. The drug administration department organized and held a symposium on the full amount guarantee of some basic drugs for the elderly over 65 years old at the grassroots level, 2015. Available: http://www.nhc.gov.cn/yaozs/s3586/201504/d19d3770819e4dea b79ef8aa3a2a1a45.shtml [Accessed 5 Dec 2019].

24 Naylor MD. A decade of transitional care research with vulnerable elders. J Cardiovasc Nurs 2000;14:1-14.

25 Shahsavari H, Zarei M, Aliheydari Mamaghani J. Transitional care: concept analysis using Rodgers' evolutionary approach. Int J Nurs Stud 2019;99:103387.

26 Xie XF, CP X, Ji H. The effect of targeted information support on disease uncertainty in elderly patients with chronic heart failure. $J$ Qilu Nursing 2012;18:52-3.

27 Lin N, Dean A, Ensel WM. Social support scales: a methodological note. Schizophr Bull 1981;7:73-89.

28 Cohen S, Wills TA. Stress, social support, and the buffering hypothesis. Psychol Bull 1985;98:310-57.

29 Thoits PA. Stress, coping, and social support processes: where are we? what next? J Health Soc Behav 1995.

30 Xiao SY. Theoretical basis and research application of social support rating scale. J Clin Psychiatry 1994;02:98-100.

31 Shi XL, Geng GL, GaoJ HJN. Advances in information continuity in transitional care for elderly patients with chronic disease. Chinese Gen Pract 2019;23:499-504.

32 Chan B, Goldman LE, Sarkar U, et al. High perceived social support and hospital readmissions in an older multi-ethnic, limited English proficiency, safety-net population. BMC Health Serv Res 2019;19:334

33 Xie XF. Effect of targeted information support on disease uncertainty and BNP in elderly patients with chronic heart failure. Shandong University, 2012.

34 Guo XJ, Han L, Li L, et al. The influence of information support based on health belief model on the elderly patients with type 2 diabetes. Chinese J Gastroenterol 2017;37:5156-8.

35 Cené CW, Haymore LB, Dolan-Soto D, et al. Self-care confidence mediates the relationship between perceived social support and self-care maintenance in adults with heart failure. $J$ Card Fail 2013:19:202-10.
36 Athilingam P, Jenkins BA, Zumpano $\mathrm{H}$, et al. "Mobile technology to improve heart failure outcomes: A proof of concept paper". Appl Nurs Res 2018;39:26-33.

37 Dunn SP, Birtcher KK, Beavers CJ, et al. The role of the clinical pharmacist in the care of patients with cardiovascular disease. J Am Coll Cardiol 2015;66:2129-39.

38 Geng G, He W, Ding L, et al. Impact of transitional care for discharged elderly stroke patients in China: an application of the integrated behavioral model. Top Stroke Rehabil 2019;26:621-9.

39 Arbaje Al, Hughes A, Werner N, et al. Information management goals and process failures during home visits for middle-aged and older adults receiving skilled home healthcare services after hospital discharge: a multisite, qualitative study. BMJ Qual Saf 2019;28:111-20.

40 Marcotte L, Kirtane J, Lynn J, et al. Integrating health information technology to achieve seamless care transitions. J Patient Saf 2015;11:185-90.

41 Coleman EA, Mahoney E, Parry C. Assessing the quality of preparation for posthospital care from the patient's perspective: the care transitions measure. Med Care 2005;43:246-55.

42 Coleman EA, Smith JD, Frank JC, et al. Development and testing of a measure designed to assess the quality of care transitions. Int $J$ Integr Care 2002;2:e2.

43 Masters S, Giles L, Halbert J, et al. Development and testing of a questionnaire to measure older people's experience of the transition care program in Australia. Australas J Ageing 2010;29:172-8.

44 Bae-Shaaw YH, Eom H, Chun RF, et al. Real-World evidence on impact of a pharmacist-led transitional care program on 30- and 90day readmissions after acute care episodes. Am J Health Syst Pharm 2020;77:535-45.

$45 \mathrm{Xu} \mathrm{H}$-lan, Xiao S-yuan, Feng S-shan, et al. [Risk factors for suicide attempt among college students at Central South University]. Zhonghua Liu Xing Bing Xue Za Zhi 2004;25:288-91.

46 Liu MC, Shi WX, XH li. Analysis of the demand and influencing factors of the old service website users. Qiu Suo 2014;10:101-5.

47 Liu MC. The research on the factors of adoption website for the elderly. Economic Science Press, 2013.

48 Milholland AV, Wheeler SG, Heieck JJ. Medical assessment by a Delphi group opinion technic. N Engl J Med 1973;288:1272-5.

49 Smith AG, Brainard JC, Campbell KA. Development of an undergraduate medical education critical care content outline utilizing the Delphi method. Crit Care Med 2020:48:98-103.

50 Komorita SS, Content A. Attitude content, intensity, and the neutra point on a LIKERT scale. J Soc Psychol 1963;61:327-34.

51 Improta G, Perrone A, Russo MA, et al. Health technology assessment $(\mathrm{HTa})$ of optoelectronic biosensors for oncology by analytic hierarchy process (AHP) and Likert scale. BMC Med Res Methodol 2019;19:140.

52 Shen L, Yang J, Jin X, et al. Based on Delphi method and analytic hierarchy process to construct the evaluation index system of nursing simulation teaching quality. Nurse Educ Today 2019;79:67-73.

53 ML W. Questionnaire statistical analysis practice: SPSS operation and application. Chongqing University Press, 2010.

54 Sun W, Chou C-P, Stacy AW, et al. Sas and SPSS macros to calculate standardized Cronbach's alpha using the upper bound of the phi coefficient for dichotomous items. Behav Res Methods 2007;39:71-81.

$55 \mathrm{Li} \mathrm{F}$, Liu HS, Zha LX, et al. Revision, reliability and validity of the Chinese version of the elderly debilitation assessment scale. Acta Psychiatr Scand 2017;32:18-20.

56 Zhou WZ, Zheng SG, Jiang DD. Construction of instrument cleaning questionnaire in disinfection supply center based on Delphi method. Chinese Nursing Research, 2017: 31. 3940-4.

57 D'Souza N, de Neree Tot Babberich MPM, d'Hoore A, et al. Definition of the rectum: an international, Expert-based Delphi consensus. Ann Surg 2019;270:955-9.

58 Hasson F, Keeney S, McKenna H. Research guidelines for the Delphi survey technique. J Adv Nurs 2000;32:1008-15. 